\title{
Respiratory Sensitization \& Sickness from Welding/Burning Isocyanate Containing Paints
}

\author{
Terrence Stobbe, Ryan Westra \\ College of Public Health, University of Arizona, Tucson, USA \\ Email: tis9@email.arizona.edu
}

Received June 2014

\begin{abstract}
The purpose of this paper is to make the environmental and occupational health community aware of a serious health risk associated with the common practice of burning industrial paint off of metal surfaces during or prior to welding. On four occasions bystanders and welder/burner personnel have experienced illness as a result of being exposed to the combustion products of isocyanate paints that were being burned off metal surfaces. In each case, the burning and the exposed people were outside in an open environment where the health risk was thought to be minimal due to the open environment with nominal wind movement through the work area. In one case, the person (a burner) developed permanent sensitization to phthalic anhydride as a result of the exposure. Phthalic anhydride was determined to be decomposition product of burned isocyanate paint. In the other three cases (which involved very short exposures), between two and six people became ill but did not develop sensitization. Their symptoms included dizziness, nausea, headache, and breathing difficulty the severity of which varied from very uncomfortable to temporarily incapacitating. This paper discusses the circumstances associated with each event, the approach used to determine that phthalic anhydride was a decomposition product, and some practical things that can be done to avoid having employees become victims of exposure.
\end{abstract}

\section{Keywords}

Welding on Epoxy Paint, Burning Epoxy Paint, Welding Health Hazards, Burning Health Hazards

\section{Introduction}

A common industrial problem both in manufacturing and in maintenance is the fact that metal surfaces (usually iron or steel) must be welded together. Often, particularly in maintenance situations, these surfaces have been painted or coated with some form of corrosion resistant material. Often the material is either epoxy based or polyurethane based. These materials are used for coating because they are "self-priming, single coat corrosion protecting coatings, that provide excellent chemical and abrasion resistance, unusual flexibility, tolerance of damp substrates, and they can be applied by brush, roller, or spray on hand-tool cleaned surfaces" (various coating manufacturer SDS and product sheet websites). Another words they are quick and effective to use and they do 
the coating job well. The recommended approach (from a health and safety perspective) is to use either a wire brush or a grinder to remove the coating in the area to be welded. On some occasions, removal is attempted with some form of paint stripper, but the stripping materials are generally quite toxic and require special handling and work conditions. A third, and commonly used way of removing the coating is to use a welding torch to burn the paint off the area to be welded.

From a "production" standpoint, this is the most efficient way to remove the coating. It is quick. Compared to wire brushing or grinding, it typically less than $10 \%$ of the work time. It is effective, since it removes all of the coating which, if left on the metal, would impair the integrity of the weld. It is easy-you just start the torch, apply the flame, and watch the coating literally "go up in smoke". It requires no special training or chemical handling skills (anyone who can do production or maintenance welding can do it). It is particularly useful in maintenance work because that is often done in field (away from the production line) situations where chemicals and grinders are not readily available, and where a lot of worker time would be used going to and from the shop to get tools, chemicals etc. In some cases, it is also done to remove paint which was applied to a surface incorrectly, and there is a large area that needs to have the paint removed quickly. In this situation, wire brushing, grinding, and/or chemicals would work, but the same time constraints would apply.

So, here we have the classic workplace "occupational health \& safety" problem: what is more important, to do it quickly and efficiently or to do it the safe but slow way. In considering this question please remember that in most cases doing the unsafe way will not result in an injury or immediately observable health effect. This fact, combined with the fact that the company having the work done is in business to make money and not to provide the safest of workplaces, means that usually the quick cheap way is chosen. Similarly, for the worker, in most cases the choice will be to use the "quick and easy" way rather than the correct way because the correct way means more work for the worker with the added risk of being reprimanded for working too slowly.

Part of the reason the workers choose the "quick and easy way" is that when it comes to health hazards, they are not aware of the hazard, they have not been educated about it, typically they cannot see the effect immediately (much like cigarette smoking), and they do not think about how difficult life will be later in time when have developed lung disease or some form of cancer from their work exposures. In some case management is also unaware of a specific health hazard associated with a work activity (like burning a protective coating off a piece of metal). This is where the occupational health and environmental health professionals come into the picture. Their job is to "anticipate, recognize, evaluate, and control" workplace and environmental health hazards that may affect the workers or the general population. In this case we are talking primarily about workers, so it is the occupational health professionals (typically referred to professionally as either Occupational Hygienists or Industrial Hygienists depending on what country you are located in) that need to act to protect the workers. They can only do this to the extent that they are aware of the potential health hazards. This paper discusses some aspects of a poorly understood worker health problem that may result from the burning of coatings prior to, or during welding.

\section{Situation}

This health hazard initially came to our attention when the supervisor of a painting line in a railroad car manufacturing facility presented at an occupational health clinic complaining of severe respiratory distress. His symptoms were initially diagnosed as asthma, later to occupational asthma, and then to isocyanate exposure related occupational asthma. The third diagnosis was assumed because during further medical evaluation and industrial hygiene investigation, it was determined that some of the paints he was exposed to on the paint line were isocyanate based. At this point he was sent to a pulmonary medicine specialist who tested him for an allergic reaction to isocyanates, and it was found that he was NOT allergic to isocyanates. This led to further testing, which eventually determined that he was allergic to phthalic anhydride. Phthalic anhydride (sometimes referred to as phthalic acid anhydride) is known to be a pulmonary irritant and is capable of causing hypersensitivity pneumonitis (which has many symptoms in common with isocyanate related occupational asthma). This then led to a final diagnosis of hypersensitivity pneumonitis secondary to pthtallic anhydride exposure. The only problem with the diagnosis was the source of exposure. There was no phthalic anhydride in the paint being used in the paint shop. Here again is where the industrial hygienist enters the picture. When a worker is diagnosed with a disease thought to be work related, it is their job to determine the source of exposure and to implement control measures that will eliminate or at least significantly reduce exposures. 
Industrial hygiene follow up consisted of a series of worksite visits to evaluate possible exposure sources, and a series of interviews with the injured person and his co-workers. during this process, it was determined that the day before becoming ill, the man had used an oxyacetylene welding torch to burn the paint of a large section of a railroad car. This was done because the paint had not cured properly, and a repaint was needed. The quickest way to get the old paint off was to burn it off. The work was done outside on a side rail away from the building. The man was working alone and he was not wearing a respirator. (No one saw a need to use a respirator because burning paint is a common industrial process, it was being done outside where there was presumed to more than adequate ventilation, and no one was aware of the possible health hazard.)

A literature search quickly revealed that little was published about the combustion products created by burning epoxy and/or polyurethane paints and coatings. The situation at hand was a one-off event, so there was no easy way to duplicate it at work. Thus, there was no immediate follow up. There was receiving medical treatment but he due to his respiratory problems, he was deemed medically unable to work and placed on long term disability. This might have been the end of the story, but then at another location the burning of these paints again made people sick.

In these later cases, the following scenario applied. On three different occasions men workers as maintenance contractors doing welding at industrial facilities were directed to replace the wear strips on front end loaders. The front end loader is a type of tractor or bull dozer used to move bulk materials. The bucket on the front end where the materials is picked up and carried is made of high strength steel, and is initially coated with a corrosion resistant paint. The most forward part of the bucket has an extra section of steel welded in place to act as a wear surface so that the bucket itself does not wear out. As the wear surface is destroyed by constant friction, it can be replaced by cutting off the old wear strip and welding a new one in its place. The new strips are also coated with the corrosion resistive paint. As previously indicated, in the area to be welded, the paint must be removed prior to welding. The "quick and easy" way to do this is to burn it off. The contractors are paid by the job (not by the hour) so they want to get the work done as fast as possible. The work is done outside in the "open air" where adequate ventilation is presumed. The work is of short duration, typically less than 30 minutes. Neither the contractor nor the company hiring the contractor was aware of the potential health hazard.

Unfortunately, in each of these cases, the welder and his helper got sick. The welder was sicker than the helper suggesting a dose-response relationship. Their symptoms included dizziness, nausea, headache, and breathing difficulty the severity of which varied from very uncomfortable to temporarily incapacitating. In each case it was severe enough to have the site's safety personnel called to the scene and in one case the affected men were taken to a nearby urgent care clinic for evaluation. All of the men recovered within a couple hours of exposure and were able to return to work. No effort was made to determine if there were any long term health effects.

When this information became available to the authors, a pilot study was undertaken to try to better understand the illness producing process. This involved both a literature search, and a epoxy paint burn test. The literature search is briefly discussed in the next section. The burn test was conducted as follows. A sample of the paint was purchased from the manufacturer. The paint was applied to a set of steel sheets. A box was built to house the sheets. The box was designed with places to insert industrial hygiene sampling devices (sorbent tubes, filters, evacuated canisters, and impingers) to collect air samples which could be analyzed by an accredited laboratory. The box formed a 95\% enclosure around the steel sheets, and had a glove box type opening thru which a welder could use an oxyacetylene torch to burn off the paint. A sample of the combustion products released during the burning was then collected by the air sampling equipment. One of the authors did the actual burning while the other author and a few other people observed the process. Even though the burning was conducted outside in the open air, and it was done inside a box which retained most of the combustion products, all of the people involved except the welder experienced symptoms similar to, but not as severe as the men involved in paint burning around the wear plates. Only the other author was aware of the welding contractors response to the burning they had done.

\section{Discussion}

As indicated, the literature search revealed that little is known about the combustion products of these coatings. The most useful references identified phenol, Biphenyl A, and phthalic anhydride as common combustion products (Eckerman, 1990; Engstromm 1990; Cook, 2002). These combustion products are similar to those found in our study, with the exception of the BPa which we did not find. This may be due to a different but similar paint being used in their studies. It may also be due to a difference in combustion temperatures, since studies have 
shown that combustion products can vary as a function of combustion temperature (Herpol 1976; Lepchek, 2004). In all cases, the contaminant concentrations were less than $20 \%$ of the OSHA and ACGIH recommended workplace exposure levels (ACGIH, 2013; OSHA Regulation 1910.1000, 2014). Clearly, in the case of this type of exposure, the applicable exposure standards are not low enough to protect exposed workers.

It is interesting to note that the MSDS (or SDS) supplied by the manufacturer (it lists 22 compounds that are initially present as the paint is applied including two epoxy compounds and an "amine adduct" which is a trade secret) does an excellent job of complying with the applicable hazard communication standard (OSHA 1910.1200 in the USA) without mentioning anything about the combustion products associated with burning the paint. While it is true that the exact products would be difficult to predict given their variability due to combustion conditions, it does seem that it would be helpful to warn workers and safety persons about the most severe of the hazards and how they might be avoided.

\section{Recommendation}

OSHA has a construction standard that applies to welding work (1926.354 Welding, cutting, and heating in way of preservative coatings). It states: "In enclosed spaces, all surfaces covered with toxic preservatives shall be stripped of all toxic coatings for a distance of at least 4 inches from the area of heat application, or the employees shall be protected by air line respirators, meeting the requirements of Subpart $\mathrm{E}$ of this part."

This is a correct directive, but "in enclosed spaces" is misleading. All of the events previously described occurred in the open air, and all but the first one involved short duration exposures. People reading the directive could assume that outside an enclosed area precautions are un necessary.

The balance of the OSHA directive addresses the issue of flammability which while a relevant safety issue, is not related to the problem at hand. The OSHA General Industry Standard, 1910. 252 addresses a variety of safety and fire related issues, but does not address the toxic coating issue.

In modern times, people who are curious about health hazards, usually turn to the internet. A review of internet comments about welding/burning on epoxy paints/coatings is mostly unhelpful. Much of it is devoted to the hazards of welding on lead containing materials, which is not relevant to the toxic coatings issue. One site briefly addressed the industrial hygiene issues with the following comments: "Every effort should be made to try and remove all protective coatings. There are instances where metal is sandwiched together and it is impossible to access the backside of the metal or the beam extends into the building structure. In these instances as much paint as possible must be removed, proper respiratory protection worn, and proper ventilation must be used to capture fume at the point of operation."

Here again, the information is correct but misleading. Since it suggests proper exhaust ventilation be used to capture fumes, a typical user might assume that since the work is being done outside there is proper ventilation and the hazard is removed (proper exhaust ventilation is a meaningless concept to the average person, but outside is usually assumed to be adequate).

Our recommendation is that all workers who may find themselves welding/burning on painted surfaces of any type be told about the potential hazards of burning paint. Since production demands will require them to do this work, they either need local exhaust ventilation designed by an industrial hygienist or qualified engineer, or at least they to position themselves where they will receive the least exposure (upwind). In this situation they must wear a respirator. A supplied air respirator may not be available, but a 1/2 mask organic respirator with a HEPA pre filter will significantly reduce exposure.

\section{Summary}

This paper has briefly discussed the poorly understood problem of the health hazards associated with welding/burning painted metal surfaces. It briefly described the primary reasons these exposure will continue to occur. Phthalic anhydride in particular was identified as the cause of permanent disability in one worker, and the combustion products of paints were identified as making multiple persons sick on a number of occasions. The lack of useful or properly protective regulatory guidelines was identified. A specific recommendation for worker protection was made.

\section{References}

ACGIH (2013). Threshold Limit Values for Chemical Substances \& Physical Agents. 
Henriks-Eckerman, M.-L., Engström, B., \& ÅNÄs, E. (1990). Thermal Degradation Products of Steel Protective Paints. American Industrial Hygiene Association Journal, 51, 241-244. http://dx.doi.org/10.1080/15298669091369592

Engström, B., Henriks-Eckerman, M.-L., \& Ånäs, E. (1990). Exposure to Paint Degradation Products When Welding, Flame Cutting, or Straightening Painted Steel. American Industrial Hygiene Association Journal, 51, 561-565.

Isenstein, M., \& Cook, L. (2002). Health Hazards from Burning a Chemical Agent Resistant Coating, a Polyurethane Paint. Poster Session Presented at the Annual American Industrial Hygiene Association (AIHCE) Conference No. 328.

Herpol, C. (1976). Biological Evaluation of the Toxicity of Products of Pyrolysis and Combustion of Materials Fire and Materials, 1,29 to 35 .

Levchik, S., \& Weil, E. (2004). Review Thermal Decomposition, Combustion and Flame-Retardancy of Epoxy Resins—A Review of the Recent Literature. Polymer International, 53, 1901-1929. http://dx.doi.org/10.1002/pi.1473

OSHA 1910.1000 (2014) Permissible Exposure Limits for Air Contaminants, Subpart Z. 